\title{
Risperidone induced pancytopenia: a case report
}

\author{
Nader M. Alrahili* \\ Department of Neuroscience, College of Medicine, Imam Mohammad Ibn Saud Islamic University, Riyadh, Saudi \\ Arabia
}

Received: 18 June 2021

Revised: 12 July 2021

Accepted: 13 July 2021

*Correspondence:

Dr. Nader M Alrahili,

Email: al.rahili@gmail.com

Copyright: (c) the author(s), publisher and licensee Medip Academy. This is an open-access article distributed under the terms of the Creative Commons Attribution Non-Commercial License, which permits unrestricted non-commercial use, distribution, and reproduction in any medium, provided the original work is properly cited.

\begin{abstract}
There are several case reports on hematological side effects after using antipsychotics in the literature. This case report could be the first case report of pancytopenia where laboratory work showed thrombocytopenia, lymphocytopenia, and neutropenia after using risperidone. It is about 14-year-old female presented with irritable mood and aggression started on Risperidone $0.75 \mathrm{mg}$ every night. A few weeks later she developed frequent and recurrent urinary tract infections and heavy vaginal bleeding that lasted for 5 days and reoccurred twice in the same month. Patient was admitted to internal medicine ward to investigate the cause of bleeding. No signs of splenomegaly, hepatomegaly, or lymph node enlargement were observed. All immunological workup results were negative. Bone morrow showed normal cellularity with granulocytic hyperplasia, suggesting a peripheral cause that was most likely a drug-induced effect. A provisional diagnosis of drug-induced pancytopenia was established. These hematological side effects may make physician to be more careful while prescribing risperidone and to follow the guideline of regular lab work especially CBC.
\end{abstract}

Keywords: Thrombocytopenia, Neutropenia, Leukopenia, Antipaychotic, Hematological side effect

\section{INTRODUCTION}

Hematological side effects are among the most serious and include neutropenia, leukopenia, and agranulocytosis. ${ }^{1}$ Some antipsychotics, such as clozapine, are considered to have more serious side effects than others. Clozapine is an atypical antipsychotic that is known to have the most serious yet rare hematological side effects. When starting clozapine, monitoring via weekly complete blood counts is necessary to avoid serious hematological side effects, especially neutropenia. ${ }^{2}$ While the hematological effects that clozapine can have on patients is well established, few case reports of hematological effects exist for risperidone. There are few reports illustrating cases of thrombocytopenia, neutropenia, or leukopenia resulting after the use of risperidone, and two case reports on risperidone-induced bicytopenia. ${ }^{3,4}$ Pancytopenia is defined as the reduction in the number of red blood cells, white blood cells, as well as platelets. ${ }^{5}$ In pancytopenia, white blood cell count is typically less than $4.0 \times 109 / \mathrm{L}$ (normal range $4.5-11.0 \times 10^{\wedge} 9$ ); hemoglobin is less than $13.5 \mathrm{~g} / \mathrm{dL}$ in males or $11.5 \mathrm{~g} / \mathrm{dL}$ in females (normal range $13.5-17.5 \mathrm{~g} / \mathrm{dL}$ in males and $11.5-15.5 \mathrm{~g} / \mathrm{dL}$ in females); and platelet count is less than $150 \times 10^{\wedge} 9 / \mathrm{L}$ (normal range $\left.150-450 \times 10^{\wedge} 9\right) .{ }^{6}$ To our knowledge, this case report is the first to report the side effects of pancytopenia after using risperidone.

\section{CASE REPORT}

A 14-year-old female patient presented to the child and adolescent psychiatry clinic in Imam Muhammad Ibn Saud Islamic university medical center complaining of social isolation, low mood, and disturbed sleep and appetite for one month. She did not have any death wishes or suicidal ideations. She did not have any history of hematological or 
immunological diseases. she was not consuming any kind of medications. There was no family history of hematological or immunological disease. She was started on a dose of $20 \mathrm{mg}$ per day of fluoxetine to treat major depressive episodes and she exhibited improvement after beginning treatment. After 2 months on fluoxetine $(20 \mathrm{mg}$ per day), the patient developed irritable mood and episodes of shouting and verbal aggression.

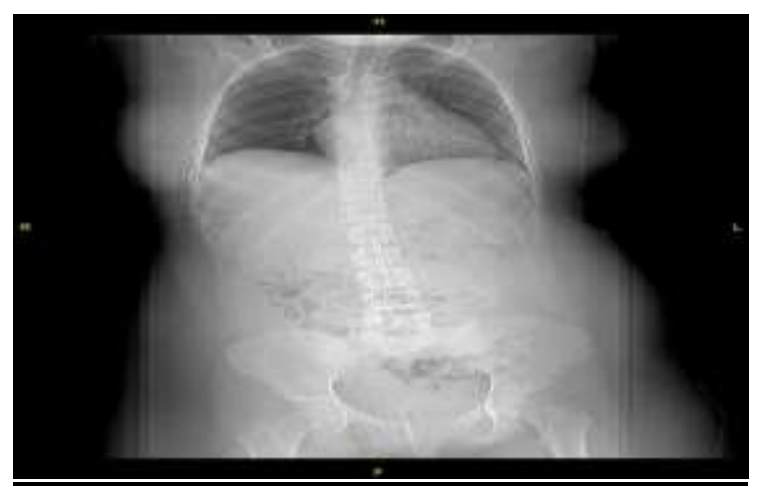

Figure 1: Frontal scoutogram of chest, abdomen and pelvis.

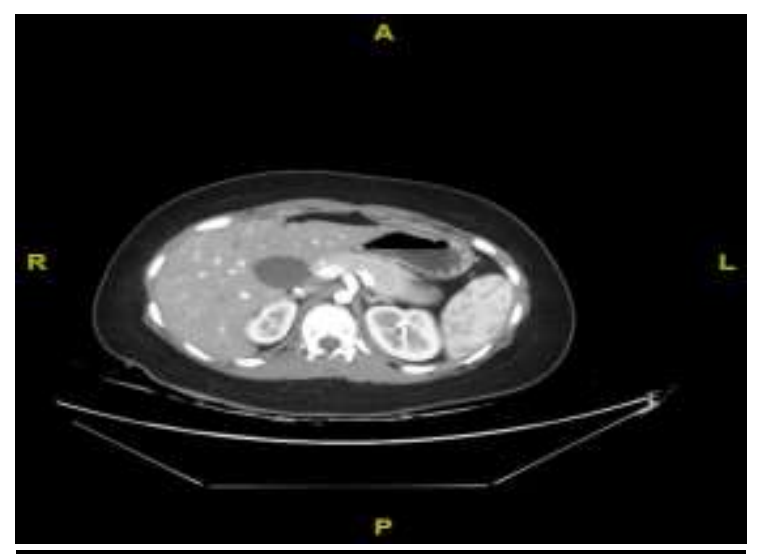

Figure 2: Enhanced axial CT scan of the abdomen.

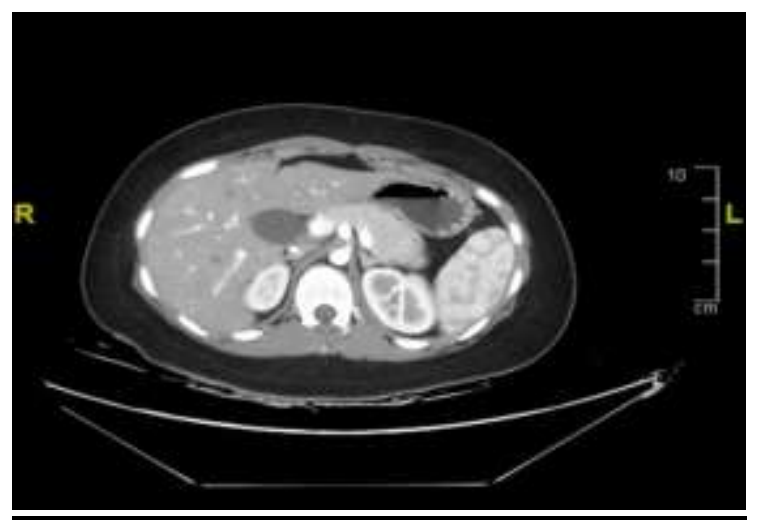

Figure 3: Enhanced axial CT scan of the abdomen.

Fluoxetine was then discontinued, and the patient was started on risperidone $0.5 \mathrm{mg}$ at bedtime to treat irritable mood and aggression. Patient improved and exhibited euthymic mood with no more episodes of shouting or aggression. Before starting risperidone and after stopping fluoxetine, there were no blood count abnormalities. The patient did not show any signs or symptoms of any hematological disease. Administration of risperidone at a dose of $0.5 \mathrm{mg}$ daily before bedtime was maintained for 9 months. After 9 months, the patient relapsed and developed aggression and disturbed behaviour. Risperidone was subsequently increased to $0.75 \mathrm{mg}$ every night. After 2 weeks of this dosing, the patient started to have frequent and recurrent urinary tract infections. A few weeks later, she experienced heavy vaginal bleeding that lasted for 5 days and reoccurred twice in the same month. She went to the emergency department and a complete blood cell count showed significant abnormalities. Her white blood cell count was $1.5 \times 109 / \mathrm{L}$, hemoglobin was $9.3 \mathrm{~g} / \mathrm{dL}$, platelet cell counts $52 \times 109 / \mathrm{L}$, and absolute neutrophil count was $0.2 \times 109 / \mathrm{L}$. The patient was admitted to the internal medicine ward to investigate the cause of the pancytopenia noted in these test results. No signs of splenomegaly, hepatomegaly, or lymph node enlargement were observed. Figure 1,2,3 All immunological workup results were negative. Bone morrow showed normal cellularity with granulocytic hyperplasia, suggesting a peripheral cause that was most likely a drug-induced effect. A provisional diagnosis of drug-induced pancytopenia was established. The patient's complete blood cell count returned to normal values 2 weeks after discontinuing risperidone, with the following results: white blood cell count, $6.9 \times 109 / \mathrm{L}$; hemoglobin, $11.3 \mathrm{~g} / \mathrm{dL}$; platelets cell count, $299 \times 109 / \mathrm{L}$; and absolute neutrophil cell count, $1.7 \times 109 / \mathrm{L}$. The patient was discharged without restarting risperidone. We did not attempt to restart risperidone in this patient, patient was discharged without any medication. In six months follow up, she showed normal values for the complete blood cell count.

\section{DISCUSSION}

There are several case reports on hematological side effects after using antipsychotics in the literature. In one such report, a 29-year-old male patient diagnosed with schizophrenia was switched from haloperidol to risperidone and developed thrombocytopenia 2 weeks after a daily dose of $8 \mathrm{mg}$. He reached full recovery a few weeks after stopping risperidone. ${ }^{7}$ Another report is of a 42-yearold male patient diagnosed with schizophrenia; he was administered $4 \mathrm{mg}$ of risperidone daily and developed thrombocytopenia during treatment. ${ }^{8}$ In another report, a 48-year-old man with a history of hypertension was admitted to the hospital because of right hemiplegia and was started on risperidone ( $1 \mathrm{mg}$ twice a day) because he was exhibiting delirium. Two weeks later, he developed thrombocytopenia. His platelets returned to normal 4 days after stopping risperidone. ${ }^{9}$ Similarly, a case of neutropenia because of risperidone intake in a 44-year-old male patient diagnosed with schizophrenia was resolved after stopping risperidone. ${ }^{10}$ Risperidone was also reported to cause bicytopenia in a 29-year-old male patient with known psychosis, after administration of $4 \mathrm{mg}$ of risperidone daily 
for 6 months with questionable compliance. He was admitted to the inpatient unit and his risperidone intake was monitored; he developed lymphocytopenia and neutropenia (bicytopenia). The patient was switched to another antipsychotic, and his lymphocyte and neutrophil counts were back to normal within 10 days. ${ }^{3}$ Another study reported a 64-year-old female patient diagnosed with bipolar affective disorder who was switched to risperidone after a depressive episode. Four weeks later, her laboratory parameters showed lymphocytopenia and neutropenia. After stopping risperidone and switching to another antipsychotic, her laboratory parameters returned to normal. ${ }^{4}$

This could be the first case report of pancytopenia where laboratory work showed thrombocytopenia, lymphocytopenia, and neutropenia after using risperidone. Pancytopenia can be caused by bone suppression or peripheral causes such as drugs or infections. ${ }^{5}$ In this case, other causes of pancytopenia were investigated before the diagnosis of risperidone-induced pancytopenia. Before the patient was started on risperidone, she did not show any signs or symptoms of any hematological disease nor did she have past or family history of hematological or immunological disease. Since the only medication she was receiving was risperidone, we considered that it was the most likely cause of the induced pancytopenia. Patient blood works were back to normal after two weeks of stopping risperidone suggesting risperidone inducing Pancytopenia. We could not rechallenge Risperidone to see if these symptoms could reappear again. It would be unethical to do such thing to a child and it was a limitation to this study. One interesting finding is that the risperidone dose in this case was much lower than other case reports. In this case, the risperidone dose that caused pancytopenia was only $0.75 \mathrm{mg}$ daily while other cases, ranged between $2 \mathrm{mg}$ and $8 \mathrm{mg}$ daily.

\section{CONCLUSION}

This case report may emphasize the importance of regular blood work of any patient receiving risperidone regardless of which dose the patient is receiving. Further studies focusing on hematological side effects of risperidone could change guidelines of blood work when starting the medication.

\section{ACKNOWLEDGEMENTS}

I am grateful to Elsevier Language Editing Services for editing the article and to my colleague Dr. Mansour Alharthi who encouraged me to write this case report and helping to export the images related to the case.

Funding: No funding sources

Conflict of interest: None declared

Ethical approval: Not required

\section{REFERENCES}

1. Flanagan, Robert J, Dunk L. Haematological toxicity of drugs used in psychiatry. Human Psychopharmacology: Clinical and Experimental. 2008;23:S27-41.

2. Lieberman, Jeffrey A. Maximizing clozapine therapy: managing side effects. The Journal of clinical psychiatry. 1988;59(3):38-43.

3. Muhammad R. Bicytopenia: adverse effect of risperidone. Current Psychiatry. 2014;13(4):E1.

4. Hung, Yuan C, Bai YM. Risperidone-induced Leukopenia and Neutropenia. Taiwanese Journal of Psychiatry (Taipei). 1988;25(2):119.

5. Jerome G. Approach to pancytopenia: Diagnostic algorithm for clinical hematologists. Blood reviews. 2018;32(5):361-7.

6. Chiravuri S, De Jesus O. Pancytopenia. In: StatPearls. Treasure Island (FL): StatPearls Publishing; 2020. https://www.ncbi.nlm.nih.gov/books/NBK563146/. Accessed on

7. Badii A, Chebbi W, Mhalla A, Soumaya F, Nadia F, Karim A et al. Risperidone-induced thrombocytopenia. 2017;(6):926-30.

8. Dipanjan B. Risperidone induced isolated thrombocytopenia: a rare adverse event. Psychopharmacology bulletin. 2018;48(3):47.

9. Jun'ichi S, Okui S. Risperidone-induced thrombocytopenia: a case report. General hospital psychiatry. 2009;31(1):97-8.

10. Kailasam, Kattalai V. Risperidone-induced reversible neutropenia. Neuropsychiatric disease and treatment. 2017;13:1975.

Cite this article as: Alrahili NM. Risperidone induced pancytopenia: a case report. Int J Basic Clin Pharmacol 2021;10:1016-8. 